\title{
A Study of Dust Aerosols Impact on Hurricanes with Multi-Sensors Measurement from Space
}

\author{
Mohammed M. Kamal ${ }^{*}$, , John J. Qu ${ }^{2}$ and Xianjun $\mathrm{Hao}^{2}$ \\ ${ }^{I}$ School of Physics, Astronomy, and Computational Sciences (SPACS), ${ }^{2}$ Environmental Science and Technology Center \\ (ESTC), and Department of Geography and GeoInformation Science (GGS), College of Science, George Mason \\ University, 4400 University Drive, Fairfax, Virginia 22030, USA
}

\begin{abstract}
MODerate resolution Imaging Spectroradiometer (MODIS) Aerosol Optical Thickness (AOT) and the Atmospheric Infrared Sounder (AIRS) atmospheric profiles (temperature and moisture) Level 2 products are studied to investigate dust aerosols impacts on hurricanes through spatial analysis. Spatial regions were selected based on two concentric circles (an annulus) and segmented by left and right regions of $180^{\circ}$ each around the hurricanes center. Statistical relationships between MODIS AOT, AIRS temperature and percent relative humidity (RH) of the hurricanes Isabel (2003), Frances (2004), Katrina (2005) and Helene (2006) are presented. The variation of temperature and RH values represented in static-left, static-right, dynamic-left and dynamic-right for the $500 \mathrm{mb}, 700 \mathrm{mb}$ and $850 \mathrm{mb}$ pressure levels are analyzed to determine the impacts of dust aerosols on temperature and RH. Average AOT was found highest in Helene (0.27) than Isabel (0.23), Frances (0.18) and Katrina (0.16). Negative impacts on the atmospheric moisture levels and positive on the temperature was found by dust aerosols. This study concludes that in 2006 dust dampened the force of hurricane Helene contributing towards extremely dryer atmosphere and inhibiting the conductive to intensify the hurricane.
\end{abstract}

Keywords: Hurricane, Aerosol, Temperature, Humidity, Moisture, Optical Depth, MODIS,AIRS, MISR, Dust, AOT.

\section{INTRODUCTION}

An estimated 150 to 320 million tons of African dust are transported from Africa to the Atlantic Ocean every year [1, 2]. Extensive seasonal dust variability occurs between June and October every year over West Africa and moves toward the tropical Atlantic. Satellite data analysis and research of dust aerosol effects on hurricanes are comparatively new, it is still difficult to conclusively understand the impacts of dust on hurricane's intensity and lifetime. Although the detailed mechanisms linking dust amount to hurricane activity is still unclear, there is considerable evidence showing the suppression of hurricane development [2] by the dry and dust-laden Saharan Air Layer (SAL) [3-5].

Large amounts of dust aerosol in atmosphere backscatter incoming solar radiation significantly, resulting in a reduction in ocean surface temperatures [6]. Dust affects the weather system by interacting with incoming solar and outgoing long wave radiation and thereby changing humidity and temperature [7]. Any changes in atmospheric dust contents would create a change in the radiation balance and, inevitably, surface temperatures $[8,9]$.

The extent and the indication of the direct effect of dust depend on its optical properties, vertical distribution, cloud cover, and the albedo of the underlying surface [9]. Also, the

*Address correspondence to this author at the School of Physics, Astronomy, and Computational Sciences, George Mason University, 4400 University Drive, Fairfax, Virginia 22030, USA: Tel: (703) 582-8825;

Fax: (703) 971-0314; E-mail: mkamal@gmu.edu optical properties of dust depend on its particle size and the refractive index [10].

By definition, a hurricane is a storm system of lowpressure. Most hurricanes begin in the Atlantic as a result of tropical waves that move westward off the coast of Africa, in the Intertropical Convergence Zone (ITCZ) [11], an area of low pressure between 5 and $15^{\circ} \mathrm{N}$ of the Equator. A category 1 hurricane is born when a tropical storm reaches a wind speed of $74 \mathrm{mph}$. Hurricanes that form above the equator have wind that circulate counterclockwise. A moist environment provides the necessary energy from the ocean surface, ensuring growth and development. A rapid rise of warm, moist air from the ocean surface come in contact with cooler air, and condense into water vapor. This helps to form storm clouds; in turn, heat is released by the system into the atmosphere. This heat prolongs the condensation process, allowing warmer, moist air to flow into the brewing storm, thus intensifying and producing a spiral wind pattern around the eye of the hurricane [12]. Generally, intense winds can be found around the hurricane eye wall, which varies in size, between 20 to 25 miles in diameter. The winds and rain around a hurricane are strongest on the right side of the storm [13]. In general, hurricanes proceed in a north or northeast direction from its place of birth, along the southeast coast of North America. It loses all of its energy within days of reaching landfall.

Studies show that North Atlantic hurricanes move northward at approximately $20-30 \mathrm{mph}$. The winds move in the same rightward direction of the storm track, creating a net-wind speed between 131 and $155 \mathrm{mph}$ for a Category 4 
hurricane $[13,14]$. On the left side of the storm, the net winds move southward at approximately $93 \mathrm{mph} \mathrm{[15].} \mathrm{Despite}$ satellite observations and numerical weather predictions that have advanced the forecasting of hurricane tracks over the last two decades, there have been few improvements in forecasting hurricane strengths [16]. Hurricanes intensify when there is more precipitation in the atmosphere and surface moisture differences are the significant contributor to intensity forecast differences, while convective instability differences play a less significant role [17].

Various study suggested [4, 18] dust has a negative impact on hurricane intensities without providing any detailed statistical relationship between them and how they impact on the specific hurricanes quantitatively. The principal intent, therefore, is to study the impact of dust aerosols on the North Atlantic hurricanes and atmospheric profiles in the vicinity of the hurricane center and present the quantitative results and statistical relationship between them. The objectives to determine the quantitative values are presented below considering four hurricanes:

1. Examine dust aerosol and atmospheric profiles impact during each hurricane within the spatial range chosen between the two concentric circles called an annulus which was divided into left and right side. These two regions are $180^{\circ}$ degrees apart from next adjacent region:

a Staying along the path of a hurricane "dynamic-coordinate". The dynamic coordinate means measure of the dust aerosols and atmospheric profile contents by following the direction of motion of a hurricane.

b Staying in a fixed point - "static-coordinate". The static-coordinate means measure of the dust aerosols and atmospheric profile contents staying in a same point for a hurricane life span. The static point is selected at a time point when a hurricane reaches its highest wind speed at lowest pressure.

c Relationship between hurricanes and dust aerosols as well as the atmospheric profile elements for the left and right side scenarios are presented for both "a" and "b".

2. Discuss the variation of temperature and $\mathrm{RH}$ values in static-left, static-right, dynamic-left and dynamic-right for 500, 700 and $850 \mathrm{mb}$ pressure levels.

3. Measure atmospheric profile difference around each hurricane to determine warm, cold, dry and wet conditions based on "pre-hurricane" and "posthurricane" scenarios.

\section{MULTISENSORS DATA PRODUCTS}

In December 1999, a new generation multi-spectral satellite remote sensing began by launching the MODIS sensor on Terra platform. As the first MODIS sensor already orbiting in space on the Terra (EOS AM-1) satellite, the second MODIS sensor was launched on the Aqua (EOS PM1) platform in 2002. Both MODIS sensors onboard Terra and Aqua platforms monitor the environment continuously in a wide range of spectral frequencies from the blue to the thermal infra-red range. MODIS is an exceptional source for monitoring the Earth's water cycle and environment as both Terra and Aqua satellites have a sun-synchronous orbit at $705 \mathrm{~km}$ height. Aqua in ascending mode crosses the equator daily at 1:30 p.m. while Terra, in descending mode, crosses the equator at 10:30 a.m. daily.

The MODIS aerosol product measured over the ocean $[19,20]$ is assimilated based on an algorithm for the remote sensing of tropospheric aerosol, are different from the aerosol over land [21]. MODIS observed reflectances were matched to a lookup table of pre-computed reflectances for a wide range of normally observed aerosol conditions for both algorithms [22]. The reflectance is calculated from the geometry pertaining to the state of the ocean [23]. Better ocean surface characterization enables [23] the use of reflectances at seven wavelengths $(0.47,0.56,0.65,0.86$, $1.24,1.64$, and $2.13 \mu \mathrm{m})$ in the equation. The retrieved aerosol products are then represented by the best fit between observed reflectance and the lookup table [23].

The AIRS launched on Aqua platform measures atmospheric profile with its infrared spectrometer scanning between 3.7 and $15.4 \mu \mathrm{m}$ spectral range with 2378 spectral channels [24]. AIRS uses a physical algorithm for the retrieval of atmospheric profiles dependent on fast and accurate radiative transfer algorithm for computing clear-air radiances which uses approximately 300 channels to determine temperature, water, and ozone profiles [25]. The cross-track scanner of AIRS with $15 \mathrm{~km}$ resolution at nadir and $705 \mathrm{~km}$ orbital altitude, produces highly accurate global atmospheric profiles product twice every day [26, 27].

In December 1999, the NASA Earth Observing System launched Multi-angle Imaging SpectroRadiometer (MISR) aboard Terra spacecraft. It has a sun synchronous orbit that crosses the equator at about 10:30 A.M. local time, descending on the dayside of the planet. The sub-spacecraft point reaches about $82^{\circ}$ latitude. MISR has nine cameras pointed toward the Earth at nine look-angles ranging from $+70^{\circ}$ through nadir to $-70^{\circ}$ along the spacecraft ground track. Each camera focal plane contains four line arrays of 1504 photoactive pixels each, which have blue, green, red, and nearIR filters [28]. The instrument images reflect sunlight, covering equatorial latitudes about once in nine days and polar latitudes about once every two days. Each of the nine cameras views angles of MISR has four wavelengths 446, 558, 672 and $866 \mathrm{~nm}$ [29]. In this study for aerosol dust AOT measurements, MISR Level 2 aerosol products, MIL2ASAE with spatial resolution of $17.6 \mathrm{~km}$ grid was also selected [30, 31] in addition to the MODIS Level 2, MOD04/MYD04 products [32]. Spatial and temporal data for all four hurricanes were collected focusing on the hurricane center while it is moving towards the west and north-west above the ocean [33]. Landfall spatial and temporal data were not selected for this study. AIRS, MODIS (Terra (MOD) and Aqua (MYD)) data [22] were collected "from http://disc.sci.gsfc.nasa.gov and http:// ladsweb.nascom.nasa.gov respectively" and vertical information from ocean to Top of the Atmosphere (TOA) of temperature and relative humidity profiles from AIRS data were compiled. AIRS level 2 standard products, AIRS2RET provides 28 level $(0.1$ to $1100.00 \mathrm{mb})$ temperature and moisture profiles. AOT at $0.55 \mu \mathrm{m}$ from MODIS level 2 
Table 1. Four Hurricane Profiles Based on the Data* Compiled from National Hurricane Center

\begin{tabular}{|c|c|c|c|c|c|c|c|}
\hline Hurricane & Year & Formed on & Dissipated on & Peaked on & Maximum Winds (mph) & Pressure (mb) & Category \\
\hline \hline Isabel & 2003 & $09 / 06 / 2003$ & $09 / 20 / 2003$ & $09 / 12 / 2003$ & 140 & 915 & 5 \\
\hline Frances & 2004 & $08 / 24 / 2004$ & $09 / 10 / 2004$ & $09 / 01 / 2004$ & 125 & 935 \\
\hline Katrina & 2005 & $08 / 23 / 2005$ & $08 / 30 / 2005$ & $08 / 28 / 2005$ & 175 & 902 & 5 \\
\hline Helene & 2006 & $09 / 12 / 2006$ & $09 / 24 / 2006$ & $09 / 18 / 2006$ & 110 & 954 \\
\hline
\end{tabular}

"Data source http://www.nhc.noaa.gov/

aerosol products (MOD04_L2 and MYD04_L2) provides AOT between 0.47 and $2.13 \mu \mathrm{m}$.

Atmospheric profiles based on AIRS infrared and microwave bands for four hurricanes: Isabel (2003), Frances (2004); Katrina (2005) and Helene (2006) were studied to investigate the effect of dust. AOT data from MODIS sensor onboard Terra and Aqua; temperature and humidity profiles data from AIRS sensor onboard Aqua was analyzed. Analysis was performed staying along the path of the hurricanes - "dynamic-coordinates" as well as staying in a fixed point - "static-coordinate". Temporal and spatial data were collected for hurricanes: Isabel between September 07 and 18,2003 from $\left(14.50^{\circ} \mathrm{N},-37.70^{\circ} \mathrm{W}\right)$ to $\left(31.50^{\circ} \mathrm{N}\right.$, $76.10^{\circ} \mathrm{W}$ ); Frances between August 25 and September 06, 2004 from $\left(11.40^{\circ} \mathrm{N},-37.60^{\circ} \mathrm{W}\right)$ to $\left(28.60^{\circ} \mathrm{N},-83.30^{\circ} \mathrm{W}\right)$; Katrina between August 23 and 29, 2005 from $\left(23.20^{\circ} \mathrm{N}\right.$,$\left.75.50^{\circ} \mathrm{W}\right)$ to $\left(29.70^{\circ} \mathrm{N},-89.60^{\circ} \mathrm{W}\right)$ and Helene between September 12 and 24,2006 along $\left(12.5^{\circ} \mathrm{N},-23.00^{\circ} \mathrm{W}\right)$ to $\left(40.90^{\circ} \mathrm{N},-37.50^{\circ} \mathrm{W}\right)$.

Table 1 describes the anatomy of the four selected hurricanes. Hurricane Isabel formed in September 6, 2003 and dissipated on September 20, 2003. Isabel becomes a Category 5 hurricane on September 12, 2003 with highest 1minute sustained winds at $165 \mathrm{mph}$ with lowest pressure 915 mb. Frances existed between August 24, 2004 and September 10, 2004 with the highest 1-minute sustained winds at $145 \mathrm{mph}$ and lowest pressure $935 \mathrm{mb}$. Hurricane Frances reached Category 4 status on 09/01/2004. Hurricane Katrina peaked in strength on August 28, 2005, forming on August 23, 2005 and dissipating on August 30, 2005. The highest 1-minute sustained winds at $175 \mathrm{mph}$ with lowest pressure $902 \mathrm{mb}$. Hurricane Helene near peak intensity was on September 18, 2006 and thrived between September 12, 2006 and September 24, 2006, with highest 1-minute winds sustained at $120 \mathrm{mph}$ and lowest pressure at $955 \mathrm{mb}$. As we can see, both Isabel and Katrina had the strongest force of winds, however, Katrina demonstrated lowest pressure about $902 \mathrm{mb}$ and created serious damage with many casualties. On the other hand, Helene exhibited the weakest force among the four and did not even make landfall.

\section{METHODOLOGY}

Pixels close to hurricane center are usually covered by cloud, making it impossible to retrieve AOT with MODIS measurements. Thus, for this study, a unique technique has been established to select spatial coordinates to investigate aerosol optical thickness, temperature and relative humidity profiles around each hurricane. Two concentric circles with radii $\mathrm{r} 1$ and r2, in Fig. (1), were drawn with a common center approximately at the hurricane center.

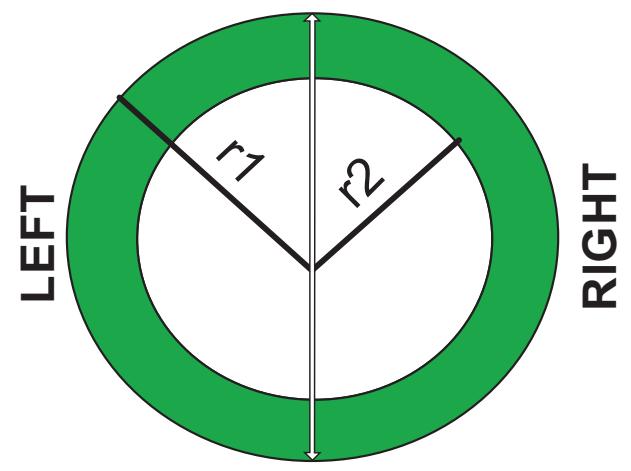

Fig. (1). Two concentric circles with two regions left and right.

The spatial regions for our analysis were chosen between the two concentric circles called an annulus which was divided into left and right side. These two regions are $180^{\circ}$ degrees apart from next adjacent region. The concentric circle annulus thickness can be adjusted by varying the radii $\mathrm{r} 1$ and $\mathrm{r} 2$.

In this study, the internal properties about the structure of the hurricanes are not considered, therefore, $\mathrm{r} 1$ and $\mathrm{r} 2$ were selected as 8 and 5 degrees respectively to produce a ring with 3 degrees annulus size. The selected region is far away from center of hurricane, but still around hurricane edge, and can get enough valid remote sensing measurements for analysis.

The two region spatial technique was applied to retrieve AOT and temperature; calculate RH from AIRS data files. For each region in Fig. (1) data were averaged and then presented for both AIRS and MODIS sensors.

An early study suggested [34] most of the dust is present between 500 and $850 \mathrm{mb}$ pressure levels. In this study, therefore, temperature and $\mathrm{RH}$ was selected at 500, 700 and $850 \mathrm{mb}$ pressure levels for each AIRS and MODIS data file for analysis. Throughout this paper results are presented based on the two spatial regions, left and right (Fig. 1). MODIS AOT data at $0.55 \mu \mathrm{m}$ and MISR AOT data at 0.558 $\mu \mathrm{m}$ were averaged and associated with the corresponding $\mathrm{RH}$ and temperature data for each of the regions. This technique has been employed on spatial area for studying hurricanes Isabel, Katrina and Helene, between the day they formed and the day they dissipated. The center of the concentric circle corresponds to the approximate location of the hurricane core. The angle within this region was further spaced out into 18 segments of $10^{\circ}$ each. Data for each $10^{\circ}$ segment was retrieved and averaged for this study resulting 18 data points for each region at a particular time and date. These 18 segments readings were then further averaged to present final average to demonstrate the values between $0^{\circ}$ and $180^{\circ}$ (left side); $180^{\circ}$ and $360^{\circ}$ (right side). For the dynamic- 
Table 2. Average AOT Values in Dynamic and Static Coordinates Presentation for Four Hurricanes

\begin{tabular}{|c|c|c|c|c|}
\hline AOT $\rightarrow$ & \multicolumn{2}{|c|}{ Dynamic-Coordinate } & \multicolumn{2}{c|}{ Static-Coordinate } \\
\hline Hurricane & MISR & MODIS & 0.17 & MODIS \\
\hline \hline Isabel & 0.23 & 0.20 & 0.14 & 0.18 \\
\hline Frances & 0.18 & 0.17 & 0.19 & 0.14 \\
\hline Katrina & 0.16 & 0.16 & 0.20 & 0.13 \\
\hline Helene & 0.27 & 0.20 & \multicolumn{2}{l}{0} \\
\hline
\end{tabular}

coordinate analysis, this concentric circles center was programmed to move with the hurricane center for each day.

AOT from MOD04/MYD04 Level 2 MODIS; temperature, $\mathrm{H}_{2} \mathrm{OMMRStd}$ and $\mathrm{H}_{2} \mathrm{OMMRSat}$ data were retrieved from Level 2 AIRS Standard product for pressure levels from 100 to $1000 \mathrm{mb}$. RH was calculated from the two AIRS data fields $\mathrm{H}_{2} \mathrm{OMMRStd}$ and $\mathrm{H}_{2} \mathrm{OMMRSat}$ as

\section{$\mathrm{RH}=\left(\mathrm{H}_{2} \mathrm{OMMRStd} / \mathrm{H}_{2} \mathrm{MMRSat}\right) * 100$}

AOT, temperature and $\mathrm{RH}$ results were than statistically presented in this paper.

MISR Level 2 aerosol product were also selected and compared against MODIS Level 2 Aerosol products. Temporal and Spatial regions were selected for four Atlantic hurricanes, Isabel (2003), Frances (2004), Katrina (2005) and Helene (2004).

Datasets were subset by latitude/longitude bounding area (Fig. 1) constructed on the spatial interest for the hurricanes and calculate daily average AOT, temperature and percent relative humidity $(\mathrm{RH})$.

\section{RESULTS AND ANALYSIS}

Dust aerosols, temperature and $\mathrm{RH}$ were observed for static and dynamic coordinate scenarios to find a pattern as well as the influences by dust on air temperature and $\mathrm{RH}$ profiles. Reduction of the RH was observed due to the increase in dust AOT levels. Dust aerosol impacts negatively on the atmospheric moisture levels. Dust aerosol impacts atmospheric temperature positively, thereby increasing AOT levels, which fuel the temperature to increase.

However, an increase in temperature is not as significant as AOT impacts reducing the moisture level. The magnitudes of dust influences are the same for both dynamic-coordinate and static-coordinate observations.

Hurricane Isabel reached the Outer Banks of North Carolina as a Category 2 hurricane with winds of $105 \mathrm{mph}$ on September 18, 2003. We found average AOT 0.20 for dynamic coordinate during its lifetime. Frances made landfall in the Gulf of Mexico and the Florida Panhandle on September 04, 2004. Average AOT for Frances was 0.17 for dynamic coordinate. On August 28, 2005, Katrina was a Category 5 storm on the Saffir-Simpson hurricane scale with winds speed approximately $150 \mathrm{mph}$ and make landfall in the Gulf of Mexico. Katrina created the most damages and carried the lowest amount of dust, with an average AOT of about 0.16 for dynamic coordinate. Hurricane Helene did not reach landfall and had sustained winds of $110 \mathrm{mph}$. AOT for the Helene was highest 0.27 for dynamic coordinate. AOT values here are the average on both regions and reported in Table 2.

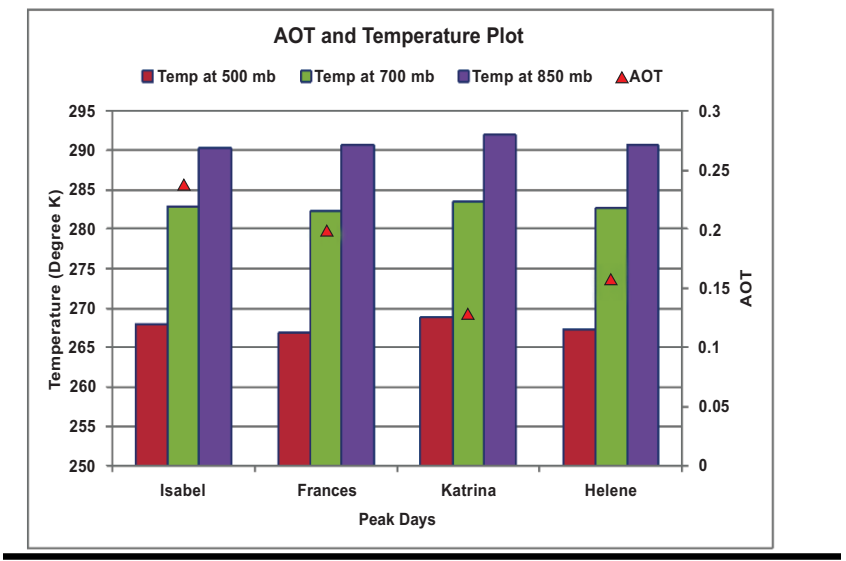

(a)

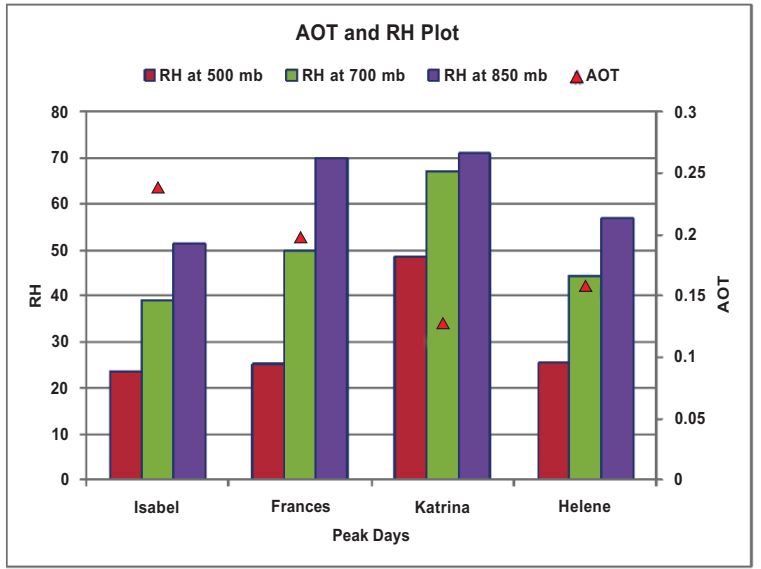

(b)

Fig (2). AIRS Temperature (a), RH (b) at 500 (RED), 700 (GREEN) and 850 (PURPLE) $\mathrm{mb}$ and MODIS AOT (RED triangles) at $0.55 \mu \mathrm{m}$ on the peak day of each hurricane by only selecting static coordinate for the analysis and left and right side data was combined to calculate the average value.

The daily average values for Level 2 MODIS MOD04 and MYD04 AOT at $0.55 \mu \mathrm{m}$ have been calculated and compared against MISR Level 2 aerosol product (MIL2ASAE) values. In Table $\mathbf{2}$, static and dynamiccoordinates AOT values from MODIS and MISR are presented. Differences in AOT values between MODIS and MISR are negligible except for the Helene's dynamiccoordinate values for MISR data. Among the four hurricanes, Isabel and Katrina reached at category 5 strengths, however, most severe damage was caused by Katrina.

Fig. (2) shows AOT values for each hurricane utilizing level 2 aerosol data from MODIS sensor on the peak day of each hurricane. Hurricane Isabel became a Category 5 on 
Table 3. AOT, RH and Temperature (in ${ }^{\circ} \mathrm{K}$ ) on the Left and Right Side of Each Hurricane Averaged for Static-Coordinate

\begin{tabular}{|c|c|c|c|c|c|c|c|}
\hline \multirow[b]{2}{*}{ Hurricane } & \multirow{2}{*}{$\begin{array}{c}\text { Pressure } \\
\text { mb }\end{array}$} & \multicolumn{6}{|c|}{ Static-Coordinate } \\
\hline & & AOT & RH & Temp & AOT & RH & Temp \\
\hline \multirow[t]{2}{*}{ Isabel } & 500 & \multirow[t]{2}{*}{0.19} & 24.86 & 266.53 & \multirow[t]{2}{*}{0.17} & 28.65 & 265.94 \\
\hline & 700 & & 43.73 & 281.87 & & 50.11 & 281.55 \\
\hline \multirow{2}{*}{ Frances } & 700 & \multirow{2}{*}{0.16} & 50.88 & 282.18 & \multirow{2}{*}{0.13} & 47.13 & 282.08 \\
\hline & 850 & & 64.87 & 290.72 & & 66.52 & 289.94 \\
\hline \multirow[t]{2}{*}{ Katrina } & 500 & \multirow[t]{2}{*}{0.13} & 48.66 & 267.91 & \multirow[t]{2}{*}{0.12} & 48.36 & 267.85 \\
\hline & 700 & & 68.42 & 283.22 & & 64.48 & 283.41 \\
\hline Helene & 850 & 0.17 & 51.00 & 290.37 & 0.18 & 49.34 & 289.97 \\
\hline
\end{tabular}

Table 4. AOT, RH and Temperature (in ${ }^{\circ} \mathrm{K}$ ) on the Left and Right Side of Each Hurricane Averaged for Dynamic-Coordinate

\begin{tabular}{|c|c|c|c|c|c|c|c|}
\hline \multirow[b]{3}{*}{ Hurricane } & \multirow{3}{*}{$\begin{array}{c}\text { Pressure } \\
\text { mb }\end{array}$} & \multicolumn{6}{|c|}{ Dynamic-Coordinate } \\
\hline & & \multicolumn{3}{|c|}{ Left Side } & \multicolumn{3}{|c|}{ Right Side } \\
\hline & & AOT & RH & Temp & AOT & RH & Temp \\
\hline \multirow{2}{*}{ Isabel } & 700 & \multirow{2}{*}{0.19} & 47.35 & 282.68 & \multirow{2}{*}{0.21} & 54.84 & 282.27 \\
\hline & 850 & & 61.24 & 290.76 & & 65.58 & 290.49 \\
\hline \multirow{2}{*}{ Frances } & 700 & \multirow{2}{*}{0.14} & 50.31 & 282.84 & \multirow{2}{*}{0.20} & 54.3 & 282.34 \\
\hline & 850 & & 61.49 & 291.18 & & 60.86 & 290.73 \\
\hline \multirow[t]{3}{*}{ Katrina } & 500 & \multirow[t]{3}{*}{0.17} & 45.34 & 268.62 & \multirow[t]{3}{*}{0.15} & 51.11 & 268.08 \\
\hline & 700 & & 64.41 & 283.40 & & 62.89 & 282.19 \\
\hline & 850 & & 70.58 & 291.52 & & 70.63 & 291.15 \\
\hline
\end{tabular}

September 12, 2003; Frances reached as a Category 4 on September 01, 2004; hurricane Katrina at peak strength on August 28, 2005 and hurricane Helene near peak intensity was on September 18, 2006. Fig. (2) illustrates AIRS Temperature, $\mathrm{RH}$ at 500, 700 and $850 \mathrm{mb}$ and MODIS AOT at $0.55 \mu \mathrm{m}$ on those peak days.

As we can see, Katrina exhibits the highest temperature and RH while AOT takes a nose dive, when compared with the other hurricanes time frame. Moreover, significant AOT variations at about 50\% had been observed during Isabel and Katrina. Temperature, $\mathrm{RH}$ and AOT have been shown for each hurricane on their peak day. Only the static coordinate were selected for the analysis; left and right side was combined to calculate the average values. Red triangles represent AOT values for the hurricanes, with Katrina conveying the lowest AOT value.
We broke down the analysis further to represent the left and right side within the static coordinate, as well as the dynamic coordinate scenarios. Table $\mathbf{3}$ and Table $\mathbf{4}$ correspond to the average AOT, RH and Temperature of both sides for hurricanes Isabel 2003, Frances 2004, Katrina 2005 and Helene 2006. AIRS temperature and RH are at 500 $\mathrm{mb}, 700 \mathrm{mb}$ and $850 \mathrm{mb}$ while MODIS AOT is at $0.55 \mu \mathrm{m}$.

We observed higher AOT values for Isabel when considering the right side of the dynamic coordinates. Also, for dynamic coordinates, the right side AOT of Helene is lower than left side. For static coordinates, left side AOT values are higher for Isabel, Frances and Katrina. This might be due to fact that in general the winds are in the same direction of the storm track along the right-hand side, hence there is a net-wind speed corresponding to Saffir-Simpson hurricane scale category and its wind speed [14]. For hurricane 


\section{AOT for Left Side}

口Left Side Dynamic $\quad \square$ Left Side Static

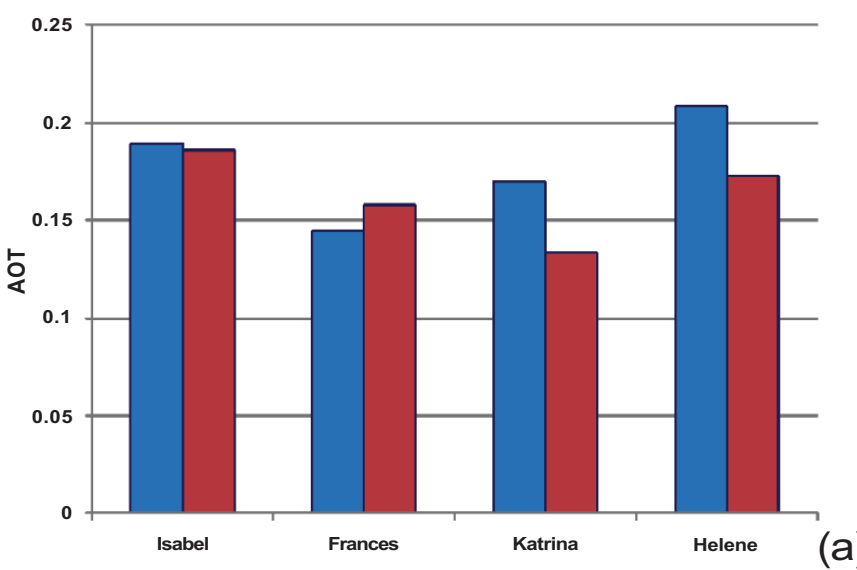

AOT for Right Side

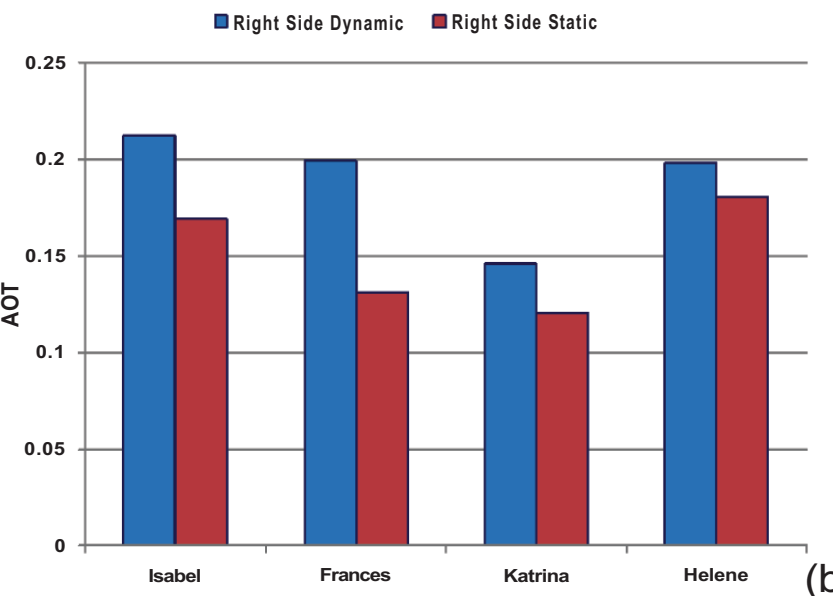

Fig (3). MODIS dynamic and static AOT at $0.55 \mu \mathrm{m}$ for left (a) and right (b) side of each hurricane.

\begin{tabular}{ll}
\hline Dynamic & Static \\
\hline & 2003, Isabel \\
\hline
\end{tabular}
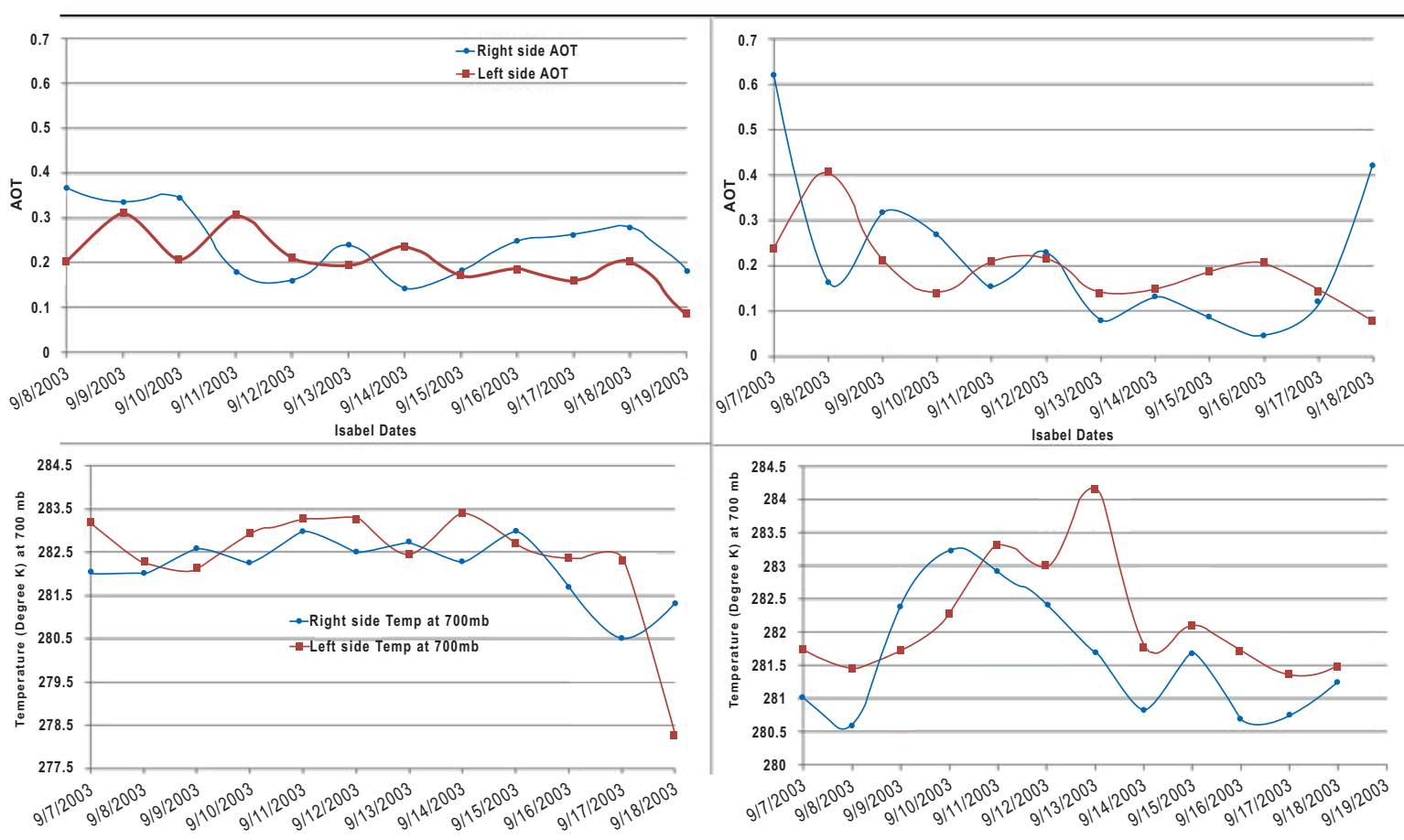

Isabel Dates
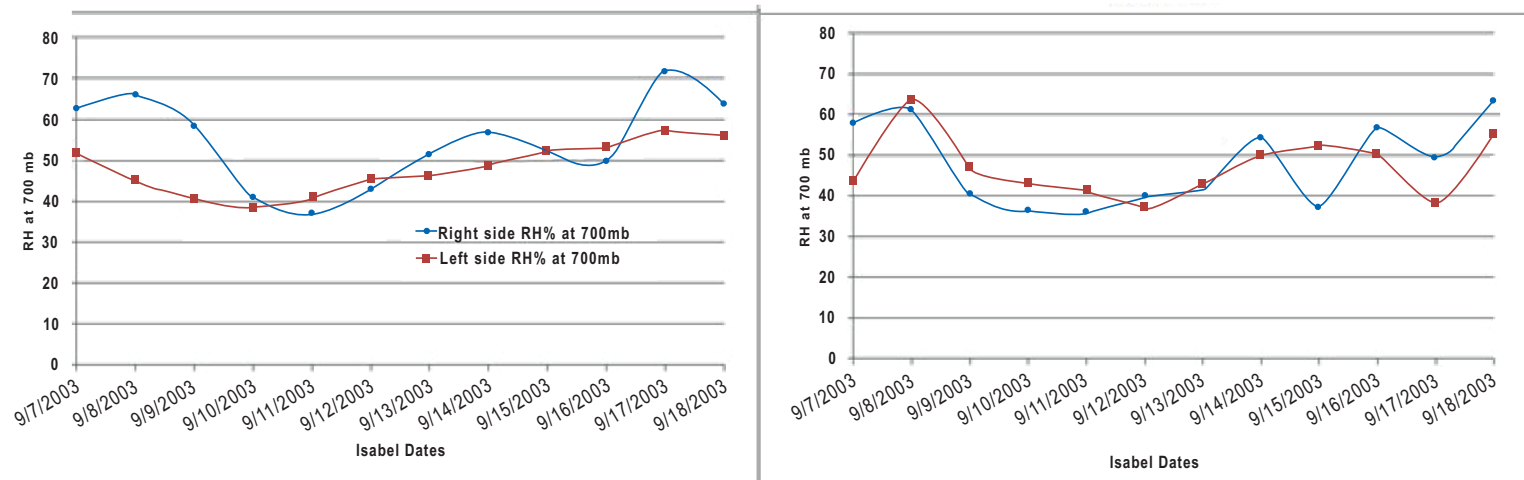

Fig (4). MODIS AOT at $0.55 \mathrm{~mm}$ and AIRS RH and temperature at $700 \mathrm{mb}$ for left and right side of hurricane Isabel (2003) showing dynamic and static conditions. 

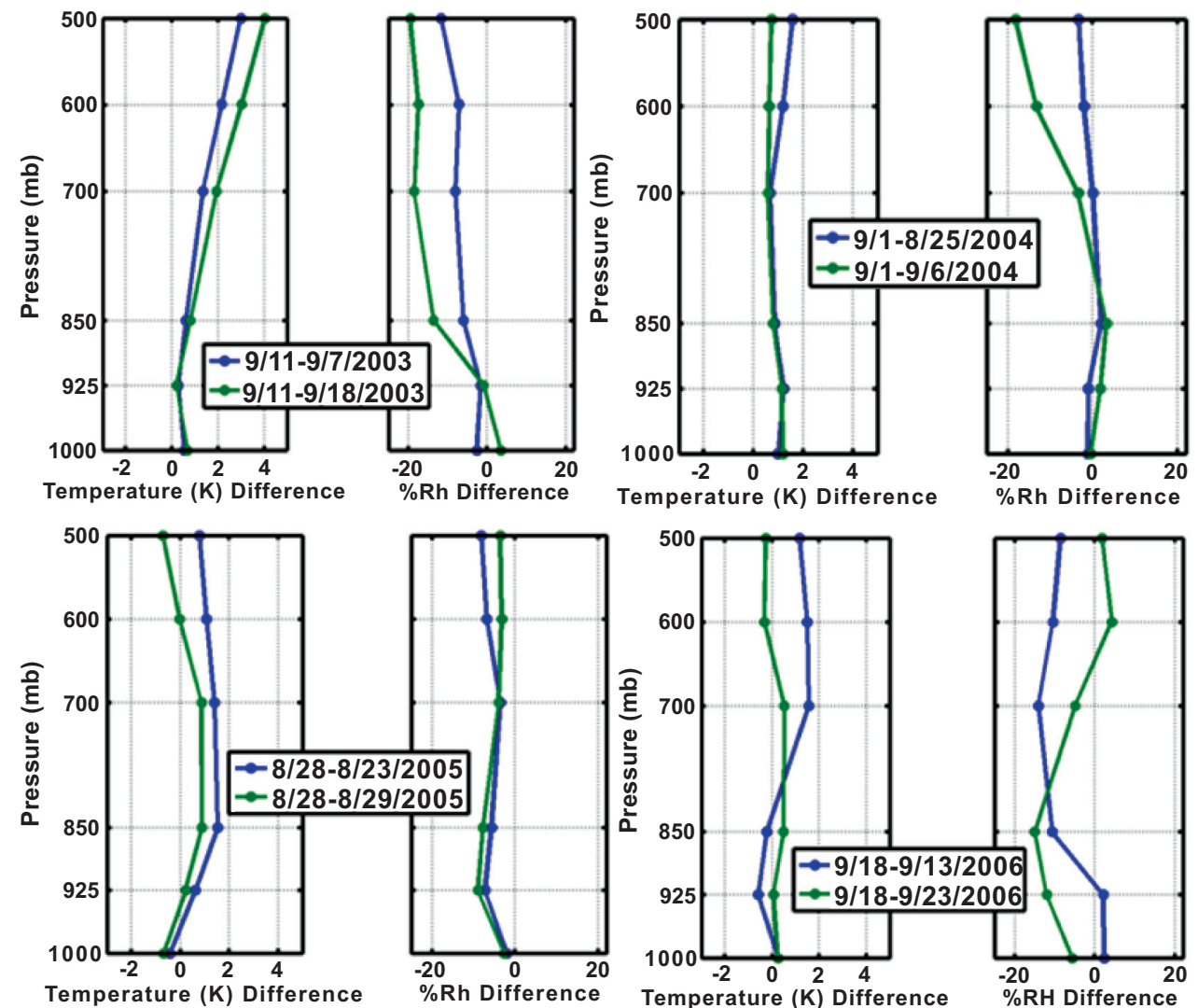

Fig (5). Temperature and RH profile difference for Isabel, Frances, Katrina and Helene from the pressure levels 500 and $1000 \mathrm{mb}$ showing "PRE" (Blue) and "POST" (Green) hurricane scenario.

Frances, on the right side, the AOT value difference between static (Table 3, $=0.13$ ) and dynamic (Table 4, $=0.20$ ) coordinates was maximum (0.07).

When the AOT values for each hurricane were averaged and plotted in Fig. (3), we see the lowest amount of dust for dynamic and static for both left and right side in case of hurricane Katrina in 2005. Isabel and Helene contained the highest amount of dust for the dynamic and static coordinate, as well as the left and right side scenarios.

On September 12, 2003, the peak day of the hurricane Isabel, as in Fig. (4), we found lower AOT (0.16) on the right side and higher AOT (0.21) on the left side for dynamic coordinate. The temperature was lower $\left(282.51^{\circ} \mathrm{K}\right)$ for dynamic coordinate on the right side while higher $\left(283.26^{\circ} \mathrm{K}\right)$ on the left side. For static coordinate, temperature was $282.39^{\circ} \mathrm{K}$ on the right and $283.02^{\circ} \mathrm{K}$ on the left side. RH for dynamic coordinate was 42.86 on the right and 45.17 on the left while for static coordinate it was 37.20 on the left and 39.91 on the right side.

When considering the peak day (September 1, 2004) of the hurricane Frances, we found lower AOT (0.15) in the left side while higher $(0.23)$ in the right side for dynamic coordinate. Values for static coordinate AOT were 0.16 and 0.25 for the left and right sides. The temperature was lower $\left(281.56^{\circ} \mathrm{K}\right)$ for dynamic coordinate on the right side while higher $\left(282.56^{\circ} \mathrm{K}\right)$ on the left side. For static coordinate, temperature was $282.03^{\circ} \mathrm{K}$ on the right and $283.73^{\circ} \mathrm{K}$ on the left side. RH for dynamic was 57.27 on the right and 46.03 on the left while for static it was 54.71 on the left and 43.06 on the right side.
On August 28, 2005, the peak day of the hurricane Katrina, we found the same amount of AOT, 0.15, both in the left side and the right side for dynamic coordinate. Values for static coordinate AOT were 0.17 and 0.20 for the left and right sides. Temperature was lower $\left(283.53^{\circ} \mathrm{K}\right)$ for dynamic coordinate on the right side while higher $\left(282.42^{\circ} \mathrm{K}\right)$ on the left side. For static coordinate, temperature was $283.54^{\circ} \mathrm{K}$ on the right and $282.81^{\circ} \mathrm{K}$ on the left side. RH for dynamic was 69.52 on the right and 58.70 on the left while for static it was 68.0 on the left and 68.04 on the right side.

For the peak day (September 18, 2006) of the hurricane Helene, we found lower AOT (0.10) in the left side while higher (0.17) in the right side for dynamic coordinate.

Clearly, for the left side and right side AOT, temperature and RH of the four hurricanes show maxima and minima for both static and dynamic coordinate scenarios, which exhibits opposite cyclic phenomena. Fig. (4) shows such cases for hurricane Isabel in 2003 for AOT and atmospheric profile at $700 \mathrm{mb}$.

Temperature and RH difference were calculated for each hurricane based on the "pre-hurricane" and "post-hurricanes" scenarios. The day in which a hurricane acquires its highest wind at its lowest pressure is considered "during-hurricane" or the reference point to calculate the "PRE" and "POST" temperature and RH profile difference. The "pre-hurricane" and the "post-hurricane" are the temporal data collection start and end dates respectively from the "during-hurricane" reference point. Fig. (5) presents vertical plots for temperature and $\mathrm{RH}$ profile difference at pressure levels 

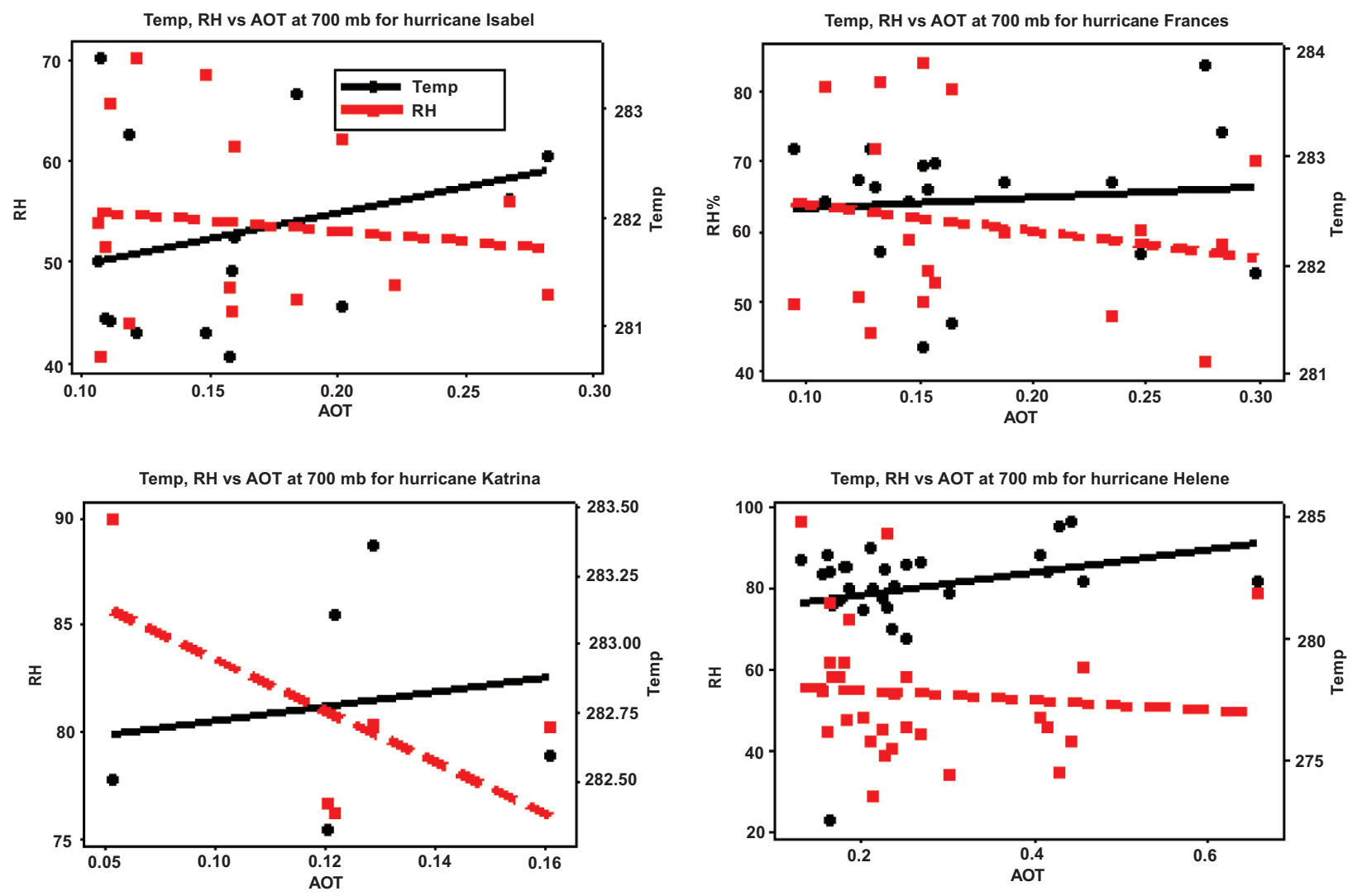

Fig (6). Scatter plot MIODIS AOT at $0.55 \mu \mathrm{m}$ and AIRS RH and temperature at $700 \mathrm{mb}$ for hurricane Isabel (2003), Frances (2004), Katrina (2005) and Helene (2006) selecting only the static coordinate and combining Terra, Aqua as well as left and right sides.

from 500 and $1000 \mathrm{mb}$ based on the AIRS data products. "PRE" which is [="during-hurricane" - "pre-hurricane"] and "POST" [="during-hurricane"-“" post-hurricane"] scenario for Isabel, Frances, Katrina and Helene are presented. In Fig (5), upper-left and lower-left plots are corresponding to Isabel and Katrina and upper-right and lower-right are corresponding to Frances and Helene. The "PRE" and "POST" curve for RH difference intersects at 550 and 925 $\mathrm{mb}$ for Isabel; and intersects at 600 and $750 \mathrm{mb}$ for Frances.

The highest "POST" RH difference observed at $700 \mathrm{mb}$ for hurricane Katrina, 2005 (lower left figure) and the lowest for hurricane Frances, 2004 (upper right figure). Also negative RH difference in "PRE" and "POST" scenarios for hurricanes Isabel and Frances and positive values for hurricanes Katrina and Helene were observed. Temperature difference at $700 \mathrm{mb}$ overlapped for hurricanes Frances and Katrina. Temperature and $\mathrm{RH}$ difference between pressure levels 500 and $1000 \mathrm{mb}$ showed small variation $\left(\sim 2^{\circ} \mathrm{K}\right)$ when compared to the significant change in RH $(\sim 15)$.

Overall for all four cases, RH ranging in pressure levels from 500 to $1000 \mathrm{mb}$ showed consistent variation within the vicinity of 15 units; however, temperature difference range was $2^{\circ} \mathrm{K}$ and consistent in all four events.

Therefore, profile difference for all four events neglecting the values closer to the surface demonstrates positive for temperature and negative for $\mathrm{RH}$. The positive temperature difference exhibits warmer and negative $\mathrm{RH}$ difference exhibits wetter condition for both "PRE" and "POST" conditions.
Table 5. Regression Equations for Each Hurricane Based on Fig. (6).

\begin{tabular}{|c|c|}
\hline Hurricanes & Regression Equations \\
\hline \hline Isabel & Temp $=281+4.83 * \mathrm{AOT}$ and $\mathrm{RH}=57.2-20.7 * \mathrm{AOT}$ \\
\hline Frances & $\mathrm{Temp}=282+0.88 * \mathrm{AOT}$ and $\mathrm{RH}=67.9-38.8 * \mathrm{AOT}$ \\
\hline Katrina & $\mathrm{Temp}=282+2.66 * \mathrm{AOT}$ and $\mathrm{RH}=95.4-120 * \mathrm{AOT}$ \\
\hline Helene & $\mathrm{Temp}=281+4.68 * \mathrm{AOT}$ and $\mathrm{RH}=57.6-12.0 * \mathrm{AOT}$ \\
\hline
\end{tabular}

As demonstrated in Fig. (6), dust aerosol impacts negatively on the atmospheric moisture levels, thereby reduced moisture levels are observed for increasing dust AOT levels when considering the scatter plot for static coordinates. Dust aerosol impacts atmospheric temperature positively, thereby, increasing AOT levels influence the temperature to increase. However, increase in temperature is not as significant as AOT impacts reducing the moisture level. For dynamic coordinates results did not follow the same trend.

Table 5. presents the regression equations for each hurricane. Insignificant $r$-squared values are found for all the four cases. This is due to the fact that hurricane depends on not only the dust aerosols and atmospheric profiles but also other variables such as wind speed, vertical shear, sea surface temperature, and relative vorticity. These additional parameters were not considered in this study. Future work will be performed to consider more variables along with 
moisture, temperature and AOT to investigate the dependency of hurricane intensity.

\section{CONCLUSIONS}

This study investigated dust aerosol impacts on hurricanes through spatial analysis of aerosol optical thickness, air temperature and relative humidity at related pressure levels. Major findings are:

1. Average AOT was lowest for the strongest hurricane while RH was significantly higher when compared with the other three hurricanes as depicted in Table 2. Suppression of RH values was observed when elevated AOT values were found (Table 2). This suppression was highest during Isabel and Helene. With the increasing AOT value there is a slight change in temperature observed in the range between 0.5 and 1.5 degrees Kelvin.

2. The daily variation of AOT, temperature and RH values in static-left, static-right, dynamic-left and dynamic-right for 500, 700 and $850 \mathrm{mb}$ pressure levels are presented in and Fig. (4). Left side and right side AOT, temperature and RH generally exhibit opposite cyclic phenomena as illustrated in Fig. (4). This behavior has been observed for all four hurricanes. For the left side and right side AOT, temperature and $\mathrm{RH}$ of the four hurricanes show maxima and minima for both static and dynamic coordinate scenarios, which exhibits opposite cyclic phenomena. Fig. (4) shows such cases for hurricane Isabel in 2003 for AOT and atmospheric profile at $700 \mathrm{mb}$. In the Tables $\mathbf{3}$ and $\mathbf{4}$, higher AOT values for Isabel when considering the right side of the dynamic coordinates was observed. Also, for dynamic coordinates, the right side AOT of Helene is lower than the left side. For static coordinates, left side AOT values are higher for Isabel, Frances and Katrina.

3. When considering the profile difference plot in Fig. (5), we found significant difference in the RH values and a small variation in the temperature for all for hurricanes. Based on the difference plot, the values found to be positive for temperature and negative for RH which corresponds to warm and dry conditions for all four hurricanes as in Fig. (5).

Among all four hurricanes, only Helene has the lowest power and intensity. Dust created an extremely dry atmosphere that was not conducive to intensifying a hurricane. As such, this study suggests that dust-ridden air influenced Helene to dissipate so that it could not intensify.

In this study we found aerosol dust values played some role to suppress Atlantic hurricanes intensity by reducing the RH and increasing temperature as described in Figs. ( 2 and 6). The implication of the present observations addressed that aerosol dust inhibits hurricane because it makes the air dry and increases the atmospheric temperature. Fueling a hurricane requires both warm and moist air, but dust is only fueling the temperature and inhibits moisture to rise. Therefore, it is dust that serves to dampen the already formed hurricane. Although Isabel and Katrina reached Category 5 strengths, Katrina created the most severe damage because of its lower pressure and higher wind speed.
Measureable lower AOT level discovered during hurricane Katrina demonstrates its intensity while significantly higher AOT observed for Isabel and Helene suggest that dust dampen their intensities.

The effect of dust on temperature and RH based on the left and right side spatial regions methodology developed for the purpose of this study, prior to this analysis, was not explored in any published material other than general comments made by authors in different text books [13, 35]. These textbooks only emphasized that the winds are the strongest around the hurricane eye wall.

It appears that, if the strongest winds are on the right side then the heaviest rains are usually on the left side (Fig. 4). Some definitive patterns were found for AOT and atmospheric profiles for both sides. However, for conclusive results, further experimentation and observation are needed. The time frame for this analysis was limited. The results in this paper are solely based on the analyses of the four hurricanes selected between 2003 and 2006. It is to be expected, therefore, that an increase in the time span, perhaps over several decades, may reveal more decisive findings.

\section{ACKNOWLEDGEMENTS}

We acknowledge the MODIS, MISR and AIRS mission scientists and associated NASA personnel for the production of the data used in this research effort. The HDF Group, http://www.hdfgroup.org, for posting code for numerous commercial and non-commercial platforms of powerful data visualization and analysis on HDF files. The authors would like to thank the reviewers for their valuable and constructive comments for improving the manuscript.

\section{CONFLICT OF INTEREST}

The authors confirm that this article content has no conflicts of interest.

\section{REFERENCES}

[1] Kaufman YJ, Koren I, Remer LA, Tanre` D, Ginoux P, Fan S. Dust transport and deposition observed from the Terra-Moderate Resolution Imaging Spectroradiometer (MODIS) spacecraft over the Atlantic Ocean. J Geophys Res 2005; 110: D10S12.

[2] Dunion JP, Velden CS. The impact of the Saharan Air Layer on Atlantic tropical cyclone activity. Bull Am Meteorol Soc 2004; 85: 353-65.

[3] Karyampudi VM, Carlson TN. Analysis and numerical simulations of the Saharan air layer and its effect on easterly wave disturbances. J Atmos Sci 1988; 45: 3102-36.

[4] Evan AT, Dunion J, Foley JA, Heidinger AK, Velden CS. New evidence for a relationship between Atlantic tropical cyclone activity and African dust outbreaks. Geosphys Res Lett 2006; 33: L19813.

[5] Hao X, Qu JJ. Saharan dust storm detection using MODIS thermal infrared bands. J Appl Remote Sens 2007; 1: 013510.

[6] Wong S, Dessler AE, Mahowald NM, Colarco PR, Silva A. Longterm variability in Saharan dust transport and its link to North Atlantic sea surface temperature. Geosphys Res Lett 2008; 35: L07812.

[7] Wielicki BA, Bruce R, Barkstrom EF, et al. Clouds and the earth's radiant energy system (ceres): an earth observing system experiment. Bull Am Meteorol Soc 1996; 77: 853-68.

[8] Houghton JT, Ding Y, Griggs DJ, et al. Intergovernmental Panel on Climate Change, Climate Change 2001. New York: Cambridge Univ Press 2001

[9] Liao H, Seinfeld JH. Radiative forcing by mineral dust aerosols: Sensitivity to key variables. J Geophys Res 1998; 103: 31637-45. 
[10] Sinyuk A, Torres O, Dubovik O. Combined use of satellite and surface observations to infer the imaginary part of the refractive index of Saharan dust. Geosphys Res Lett 2003; 30(2): 1081.

[11] Grodsky SA, Carton JA. The intertropical convergence zone in the south atlantic and the equatorial cold tongue. American Meteorological Society. J Clim 2003; 16: 723-33.

[12] Hurricanes. Available from: http://sparce.evac.ou.edu/q_ and _a/hurricanes.htm [January 21, 2012]

[13] Aguado E, Burt JE. Understanding Weather and Climate. $5^{\text {th }}$ ed. USA: Prentice Hall 2010

[14] Hurricane Basics, National Hurricane Center; Available from: http://hurricanes.noaa.gov/pdf/hurricanebook.pdf [April 26, 2012]

[15] Hurricanes (Tropical Cyclones), Prof. Stephen A. Nelson; Available from: http://www.tulane.edu/ sanelson/geol204/tropical_cyclones.htm [April 26, 2012].

[16] DeMaria MM, Mainelli LK, Shay JA, Knaff KJ. Further Improvements in the Statistical Hurricane Intensity Prediction Scheme (SHIPS). Weather Forecasting 2005; 20: 531-43.

[17] Sippel JA, Fuqing Z. Factors Affecting the Predictability of Hurricane Humberto (2007). J Atmos Sci 2010; 67: 1759-78.

[18] Sun D, Lau WKM, Kafatos M, et al. Numerical simulations of the impacts of the saharan air layer on atlantic tropical cyclone development. J Clim 2009; 22: 6230-50.

[19] Madhavan S, Qu J, Xiong J. Comparison Study between MODIS Terra and Aqua for AOT Retrieval over Ocean. Geoscience and Remote Sensing Symposium Proc. IGARSS, 3, III-515 - III-518 10.1109/IGARSS.2008.4779397, 2008.

[20] Tanré D, Kaufman YJ, Herman F, Mattoo S. Remote sensing of aerosol properties over oceans using the MODIS/EOS spectral radiances. J Geophys Res 1997; 102(D14): 16971-88.

[21] Kaufman YJ, Tanré D, Remer LA, Vermote EF, Chu A, Holben BN. Operational remote sensing of tropospheric aerosol over land from EOS moderate resolution imaging spectroradiometer. J Geophys Res 1997; 102: 17051-67.

[22] Remer LA, Kaufman YJ, Mattoo S, et al. The MODIS aerosol algorithm, products, and validation. J Atmos Sci 2005; 62: 947-73.

[23] King MD, Menzel WP, Kaufman YJ, et al. Cloud and aerosol properties, precipitable water, and profiles of temperature and humidity from MODIS. IEEE Trans Geosci Remote Sens 2003; 41: 442-58.

[24] Aumann HH, Chahine MT, Gautier C, et al. AIRS/AMSU/HSB on the Aqua mission: design, science objectives, data products, and processing systems. IEEE Trans Geosci Remote Sens 2003; 41: 253-64.

[25] Strow LL, Hannon SE, Souza-Machado SD, Motteler HE, Tobin D. An overview of the AIRS radiative transfer model. IEEE Trans Geosci Remote Sens 2003; 41: 303-13.

[26] Qu JJ, Gao W, Kafatos M, Murphy RE, Salomonson VV. Earth Science Satellite Remote Sensing. Berlin: Springer 2006; vol. 1: p.408.

[27] Aumann HH, Strow L. AIRS: the first hyper-spectral infrared sounder for operational weather forecasting. Proc of IEEE Aero Conf 2001. Mar 10-17, 2001. Big sky MT Conference Publication; vol. 4: pp. 1683-92.

[28] Diner DJ, Beckert JC, Reilly $\mathrm{TH}$, et al. Multiangle Imaging Spectroradiometer (MISR) description and experiment overview.IEEE Trans Geosci Remote Sens 1998; 36: 1072-87.

[29] Kahn RA, Nelson DL, Garay MJ, et al. MISR Aerosol Product Attributes and Statistical Comparisons With MODIS. IEEE Trans Geosci Remote Sens 2009; 47: 4095-114.

[30] Diner DJ, Davies R, Varnai T, et al. MISR level 2 top-ofatmosphere albedo algorithm theoretical basis. Jet Propulsion Laboratory. California Institute of Technology 1999.

[31] Diner DJ, Davies R, Varnai T, et al. MISR level 2 aerosol retrieval algorithm theoretical basis. Jet Propulsion Laboratory. California Institute of Technology 2001.

[32] Levy RC, Remer LA, Tanré D, Mattoo S, Kaufman YJ. Algorithm for remote sensing of tropospheric aerosol over dark targets from MODIS. Levy RC, Remer LA, Tanré D, Mattoo S, Kaufman YJ, Collections 005 and 051: Revision 2, 2009.

[33] Unisys Hurricane/Tropical Data. Available from: http://weather.unisys.com/hurricane/ [April 26, 2012]

[34] Carlson TN, Prospero JM. The large-scale movement of Saharan air outbreaks over the northern equatorial Atlantic. J Appl Meteor 1972; 11: 283-97.

[35] Ackerman SA, Knox JA. Meteorology: understanding the Atmosphere. Australia: Thomson Brooks/Cole 2007.

$\overline{\text { Received: May 26, } 2012 \quad \text { Revised: June 20, } 2012 \quad \text { Accepted: June 24, 2012 }}$

(C) Kamal et al.; Licensee Bentham Open.

This is an open access article licensed under the terms of the Creative Commons Attribution Non-Commercial License (http: //creativecommons.org/licenses/bync/3.0/), which permits unrestricted, non-commercial use, distribution and reproduction in any medium, provided the work is properly cited. 